\title{
CONTROLE DO MINÉRIO DE ESPODUMÊNIO EM PEGMATITOS DA MINA DA CACHOEIRA, ARAÇUAI, MG
}

\author{
Júlio Cezar Pimenta Romeiro (*) \& Antônio Carlos Pedrosa-Soares (**)
}

\begin{abstract}
The focused pegmatites belong to the Cachoeira Group, a spodumene-rich pegmatite population of the Araçuaí Pegmatite District, located in the north region of the Eastern Brazilian Pegmatite Province. The Cachoeira Mine (CBL-Companhia Brasileira de Lítio) is located in the low valley of the Piauí River, east of Araçuaí town, Minas Gerais. The structural control of the pegmatites and related variations in spodumene grain size are important factors for mine planning. The pegmatites of the Cachoeira Mine are non-zoned bodies with very few and small replacement pockets. They intruded along two different NE-striking surfaces of medium- to high-angle dip: the NW-dipping schistosity and the SE-dipping fracture cleavage. Systematic measurements show that the general average size of spodumene crystals decreases with depth (i.e., the deeper the pegmatite segment, the smaller the crystal size), but spodumene modal contents remain similar in different depths. Enrichment in coarse-grained spodumene crystals occurs in shallow-dipping pegmatite segments. The increasing in spodumene crystal size, from lower to upper depths, can be related to decreasing in viscosity of the silicate melt in response to accumulation of rising aqueous fluids towards the top of the pegmatite. The same effect can be expected for places of fluid swimming, such as the shallow-dipping pegmatite segments. Fluids, like $\mathrm{H}_{2} \mathrm{O}$ and $\mathrm{F}$, act by lowering the viscosity that, in turn, assists crystal growth. $\mathrm{K} /$ $\mathrm{Rb}$ and $\mathrm{K} / \mathrm{Ba}$ ratios obtained from microcline crystals, associated to the spodumene, decrease gradually from the bottom to the top of the pegmatites. Such increasing (to the top) in $\mathrm{Rb}$ and $\mathrm{Ba}$ also suggests fluid enrichment in the same way of the increasing size of spodumene crystals.
\end{abstract}

\section{INTRODUÇÃO}

O Distrito Pegmatítico Araçuaí situa-se na região noroeste da Província Pegmatítica Oriental do Brasil (e.g., PedrosaSoares etal. 2001a). O Grupo Pegmatítico da Cachoeira é uma população de pegmatitos que, no Distrito Araçuaí, se distingue pelo alto conteúdo de espodumênio e quantidades significativas de outros minerais de lítio (Romeiro et al. 1997). Em relação ao sistema de classificação de Cerný (1991), os pegmatitos do Grupo da Cachoeira enquadram-se na família LCT ( $\mathrm{Li}, \mathrm{Cs}, \mathrm{Ta})$ da classe de pegmatitos com elementos raros, que se associam a granitos tardi-orogênicos. Os pegmatitos do Grupo da Cachoeira são produtos da cristalização de resíduos magmáticos de intrusão granítica da Suíte G4. Esta suíte representa um episódio de granitogênese tipo $S$, ocorrido entre 530 e $500 \mathrm{Ma}$ (Pedrosa-Soares et al. 2001a,b).

A Companhia Brasileira de Lítio(CBL) implantou a Mina da Cachoeira no baixo vale do Rio Piauí, afluente do Jequitinhonha a leste da cidade de Araçuaí (Figura 1), para extrairminério de espodumênio de pegmatitos, com a finalidade de alimentar sua planta industrial produtora de óxido e carbonato de lítio.

O presente trabalho sintetiza estudos sistemáticos efetuados pelos autores sobre pegmatitos da Mina da Cachoeira. O estabelecimento do controle estrutural dos pegmatitos, além de subsidiar o planejamento da lavra, é ferramenta essencial para o entendimento das variações de granulação do minério de espodumênio que, por sua vez, é também um importante fator econômico. O monitoramento geoquímico permite avaliar aspectos petrogenéticos relacionados ao crescimento dos cristais de espodumênio. As tabelas completas de dados quantitativos, além de informações mais detalhadas, se encontram em Romeiro(1998).

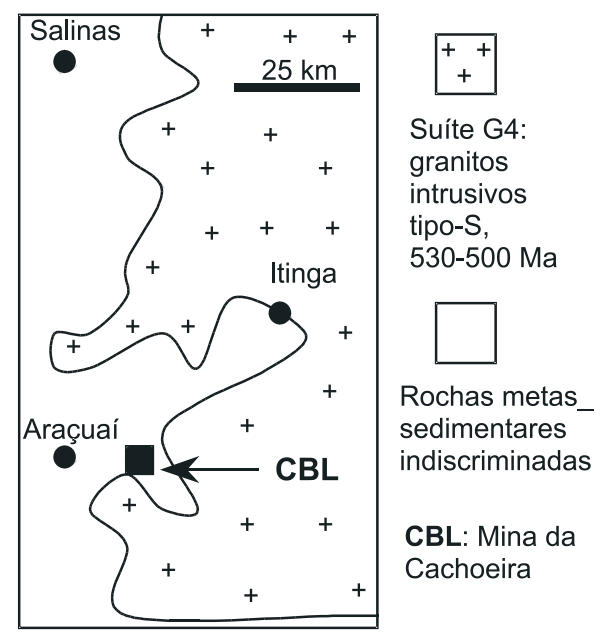

Figura 1. Mapa de localização da Mina da Cachoeira, Companhia Brasileira de Lítio. 


\section{CARACTERÍSTICASGERAIS}

Os pegmatitos da Mina da Cachoeira estão encaixados em um pacote de biotita xistos, geralmente ricos em cordierita, com intercalações de rochas cálciosilicáticas (Figura 2, fotos A, B e D). As rochas encaixantes da área da mina eram consideradas como pertencentes à Formação Salinas (e.g., Pedrosa-Soares et al. 2001b). Entretanto, em função da recente revisão estratigráfica regional (Lima et al. 2002, Pedrosa-Soares et al. 2005) e do mapeamento em escala 1:100.000 (em realização pela CPRM), o posicionamento estratigráfico deste pacote de xistos pode vir a ser revisto.

Os pegmatitos da Mina da Cachoeira mostram significativa regularidade nas suas características morfológicas e mineralógicas. São corpos tabulares com continuidade lateral marcante, geralmente de centenas de metros, ao longo da direção e do mergulho. Suas terminações tendem à forma lenticular e podem mostrar interdigitações de apófises pegmatíticas com as rochas encaixantes. A espessura média dos corpos varia entre 3 e $4 \mathrm{~m}$ (Figura 2, foto D). Os contatos destes pegmatitos com as rochas encaixantes são marcantemente bruscos
(Figura 2, fotos B e D).

A despeito de suas dimensões avantajadas, os pegmatitos da Mina da Cachoeira são homogêneos, ou seja, são corpos sem zoneamento interno. Os corpos de substituição tardios (incluindo geodos) são muito raros e pequenos. Entretanto, os pegmatitos da Mina da Cachoeira mostram variações de granulação que, mesmo não sendo caracterizáveis como zonas de cristalização primária, têm sua importância econômica para a lavra e valor do minério.

Os pegmatitos da Mina da Cachoeira são constituídos essencialmente por microclina pertítica, espodumênio, albita, quartzo e moscovita. Os minerais acessórios mais comuns são montebrasita, berilo, cassiterita e columbo-tantalita.

Os cristais de espodumênio podem atingir dimensões de até um metro e meio, sendo que seu tamanho médio oscila entre 10 e $20 \mathrm{~cm}$ (Figura 2, fotos B e C). Geralmente são cristais tabulares segundo a face $\{100\}$. Cristais geminados segundo $\{100\}$ são também freqüentes. A clivagem $\{110\}$ é claramente notada nos cristais. Sua cor característica é verde pálido, porém tons amarelados e brancos também são comuns.
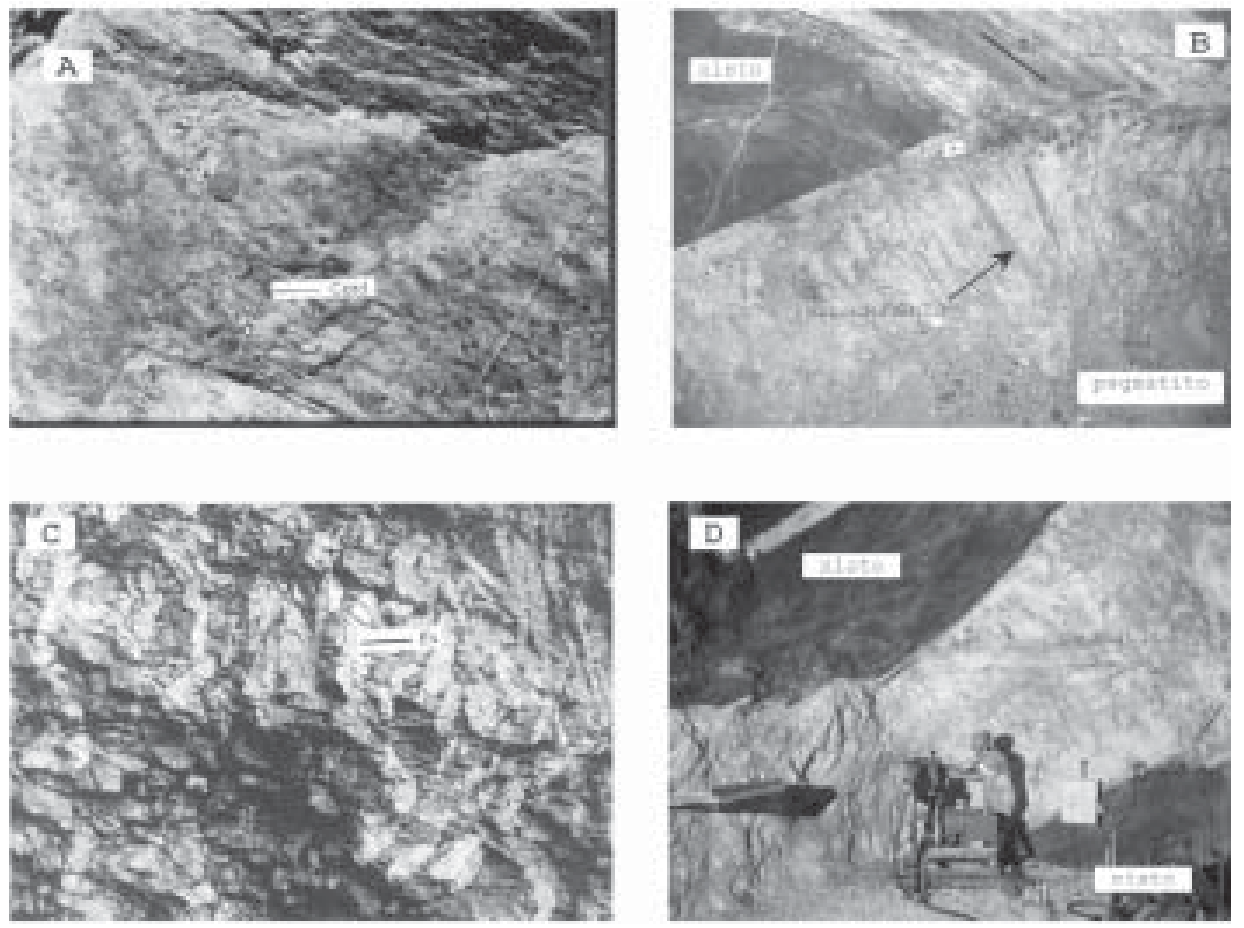

Figura 2. Fotos de pegmatitos e suas rochas encaixantes na Mina da Cachoeira (reproduzidas com a permissão da Companhia Brasileira de Lítio). Foto A: biotita xisto, rico em cordierita (na forma de poiquiloblastos circulares de cor negra), encaixante dos pegmatitos da Mina da Cachoeira. Foto B: contato

brusco entre xisto e pegmatito discordante da foliação principal (Sp) da rocha encaixante; o pegmatito apresenta delgada banda de grão fino (chilled margin) no contato, evidenciando o choque térmico do magma pegmatítico $\left(550-600^{\circ} \mathrm{C}\right)$ durante seu alojamento pós-tectônico no xisto encaixante $\left(\sim 200^{\circ} \mathrm{C}\right)$; os cristais de espodumênio estão dispostos ortogonalmente ao contato. Foto C: pegmatito muito rico em cristais de espodumênio, fato comum na Mina da Cachoeira; a barra tem $15 \mathrm{~cm}$. Foto D: pegmatito de 3 a $4 \mathrm{~m}$ de espessura, em lavra subterrânea. 


\section{CONTROLE ESTRUTURAL}

Estruturas planares das rochas encaixantes geralmente exercem significativo controle sobre a forma e atitude dos pegmatitos, mesmo quando estes são póscinemáticos em relação à gênese das estruturas encaixantes (Cerný 1991, Pedrosa-Soares et al. 1997).

No caso da Mina da Cachoeira, o estudo do controle estrutural dos pegmatitos, além de subsidiar o planejamento da lavra, é ferramenta essencial para o entendimento das variações de granulação do minério de espodumênio.

As rochas encaixantes destes pegmatitos apresentam uma xistosidade principal (Sp) que tem direção NE e mergulho NW. A média das medidas de Sp efetuadas na área da mina indica direção a N52E, com mergulho de $43^{\circ}$ para NW (Figura 3 ).

A fase de deformação rúptil é marcada por três famílias de clivagens de fratura. A Família 1 tem direção NE, mas apresenta ângulos de mergulho muito diferentes, de sub-horizontal a sub-vertical, para SE. A Família 2 tem direção E-W e mergulho médio a alto para S. A Família 3 tem direção NW e é sub-vertical (Figura $3)$.

Os pegmatitos do Grupo da Cachoeira alojaram-se ao longo da xistosidade $\mathrm{Sp}$ ou das clivagens de fratura, evidenciando o caráter pós-deformacional destes corpos. Os corpos G2-7 e G3-6 são exemplos de pegmatitos concordantes com a xistosidade principal da rocha encaixante (Figura 3). Os corpos G1-8 e G4-5 estão encaixados segundo a clivagem de fratura da Família 1 (Figura 3), sendo claramente discordantes da xistosidade $\mathrm{Sp}$ (Figura 2, foto $\mathrm{B}$ ).

O corpo G4-5, objeto de estudos mais detalhados, é discordante de $\mathrm{Sp}$ e está encaixado pela clivagem de fratura da Família 1, com direção NE e ângulos de mergulho variáveis (sub-horizontal a sub-vertical) para SE. O corpo G4-5 tende a sub-vertical em profundidades superiores ao nível N-308 e, em função das irregularidades dos contatos, pode mostrar mergulho local para NW.

Os pegmatitos da Mina da Cachoeira arranjam-se em tramas de diques tabulares e descontínuos, com terminações lenticulares, que seguem um padrão escalonado (en échellon). Nos locais de fechamento dos corpos são constantes as inversões de mergulho e presença de grande quantidade de apófises. Este arranjo pode ser explicado pela concorrência entre fatores tais como variação de competência das rochas encaixantes (que oferecem resistência diferencial à entrada do magma) e variações de suprimento e viscosidade do magma pegmatítico.

\section{VARIAÇÃODE GRANULAÇÃO}

A granulação de alguns minerais constituintes dos pegmatitos é, muitas vezes, um fator determinante para torná-los economicamente exploráveis.

No caso da Mina da Cachoeira, até recentemente, quanto maior os cristais de espodumênio, maior o grau de liberação na correia da linha de catação e maior a produção diária, considerando a mesma frente de lavra. Atualmente, a Companhia Brasileira de Lítio opera com o sistema de separação do espodumênio e feldspato em planta de meio denso. Entretanto, a granulação continua sendo um fator diferencial para a operação da lavra.

A granulação do espodumênio é variável nos diversos corpos que compõem o Grupo Pegmatítico da Cachoeira.

O corpo G1-8 mostra granulação relativamente grossa quando comparado aos outros corpos. Neste corpo, os cristais de espodumênio do nível N-300 possuem tamanhos que variam de 20 a $30 \mathrm{~cm}$ no seu maior comprimento (paralelo à face $\{100\}$ ) e espessuras da ordem de 3 a $5 \mathrm{~cm}$.

O corpo G2-7 mostra a menor granulação, variando de média a grossa, comparativamente. Os cristais de espodumênio variam de 10 a $20 \mathrm{~cm}$ de comprimento e têm espessura entre 2 e $3 \mathrm{~cm}$.

O corpo G3-6 mostra orientação linear dos cristais de espodumênio, crescidos com a face $\{100\}$ ortogonalmente aos contatos, refletindo o resfriamento centrípeto da fusão silicatada (Figura 2, foto C). Este corpo tem granulação grossa e contém cristais com comprimentos que variam de 15 a $30 \mathrm{~cm}$, na galeria $\mathrm{N}$ 300.

A variação da granulação do corpo G4-5 foi mapeada detalhadamente, em paralelo ao estudo do controle estrutural. Coletaram-se dados referentes ao tamanho dos cristais de espodumênio, desde o topo do corpo (nível N-313) até o nível N-226 (Romeiro 1998). Os termos topo e base são aqui usados em sentidos diversos de capa e lapa. Considera-se que capa e lapa dizem respeito às superfícies limitantes da espessura do corpo. Por sua vez, topo e base referem-se às extremidades do corpo em relação à profundidade, ou seja, a "cabeça" e o "pé", respectivamente.

Do tratamento das medidas tomadas no corpo G4-5 resultou o histograma que ilustra a distribuição dos tamanhos dos cristais de espodumênio versus sua posição em relação aos níveis subterrâneos e ao mergulho do pegmatito (Figura 4). Nota-se a tendência de diminuição da granulação do topo para a base do corpo G4-5. O topo do corpo G4-5 (nível 313 e acima) registra a presença de grandes cristais, que medem entre 1 e 2 m segundo o maior comprimento.

Destaca-se, também, a variação da granulação no segmento mediano (nível 265 a nível 252) do corpo G4-5, onde o mergulho diminui $\left(30^{\circ}\right)$ e ocorrem cristais maiores (de até $1 \mathrm{~m}$ de comprimento) concentrados do lado da capa. Neste local ocorre uma concentração anormal de grandes cristais de espodumênio (Figura 4).

A variação no tamanho dos cristais nos níveis inferiores (N-239, N-226, N-213) do corpo G4-5 é muito pequena. Em média, o tamanho dos maiores cristais varia entre 30 e $45 \mathrm{~cm}$. De fato, cristais maiores são muito raros nos níveis inferiores do corpo G4-5.

Os dados sintetizados na Figura 4 remetem para uma interpretação relacionada à viscosidade do magma 
pegmatítico em processo de cristalização. Tomando como premissas um conteúdo regular de lítio em todo o pegmatito e diferenças desprezíveis de temperatura e tempo de resfriamento entre topo e base do pegmatito, a variação de granulação pode ser relacionada à diminuição de viscosidade da fusão silicatada. Menor viscosidade induz diminuição na densidade de nucleação que, por sua vez, permite o crescimento de cristais maiores.

Desta forma, interpreta-se que o aumento na granulação do espodumênio, que ocorre no segmento superior do pegmatito ou em locais onde o corpo apresenta mergulho baixo, se deve à diminuição da viscosidade do magma. Esta diminuição de viscosidade pode ser promovida pelo acúmulo de fluidos aquosos durante a cristalização primária do pegmatito. $\mathrm{O}$ acúmulo de fluidos aquosos ascendentes induz a diminuição da viscosidade e, conseqüentemente, a diminuição da densidade de nucleação na fusão silicatada. O resultado disto é a cristalização de um número menor de cristais, mas com maiores dimensões (Figura 4).

Pedrosa-Soares et al. (1997) discutem o efeito de ascensão dos fluidos (efeito updip) em pegmatitos homogêneos, que é o caso da Mina da Cachoeira. Este efeito condiciona o acúmulo localizado dos fluidos no topo do corpo e onde o pegmatito apresenta mergulho baixo (Figura 5).

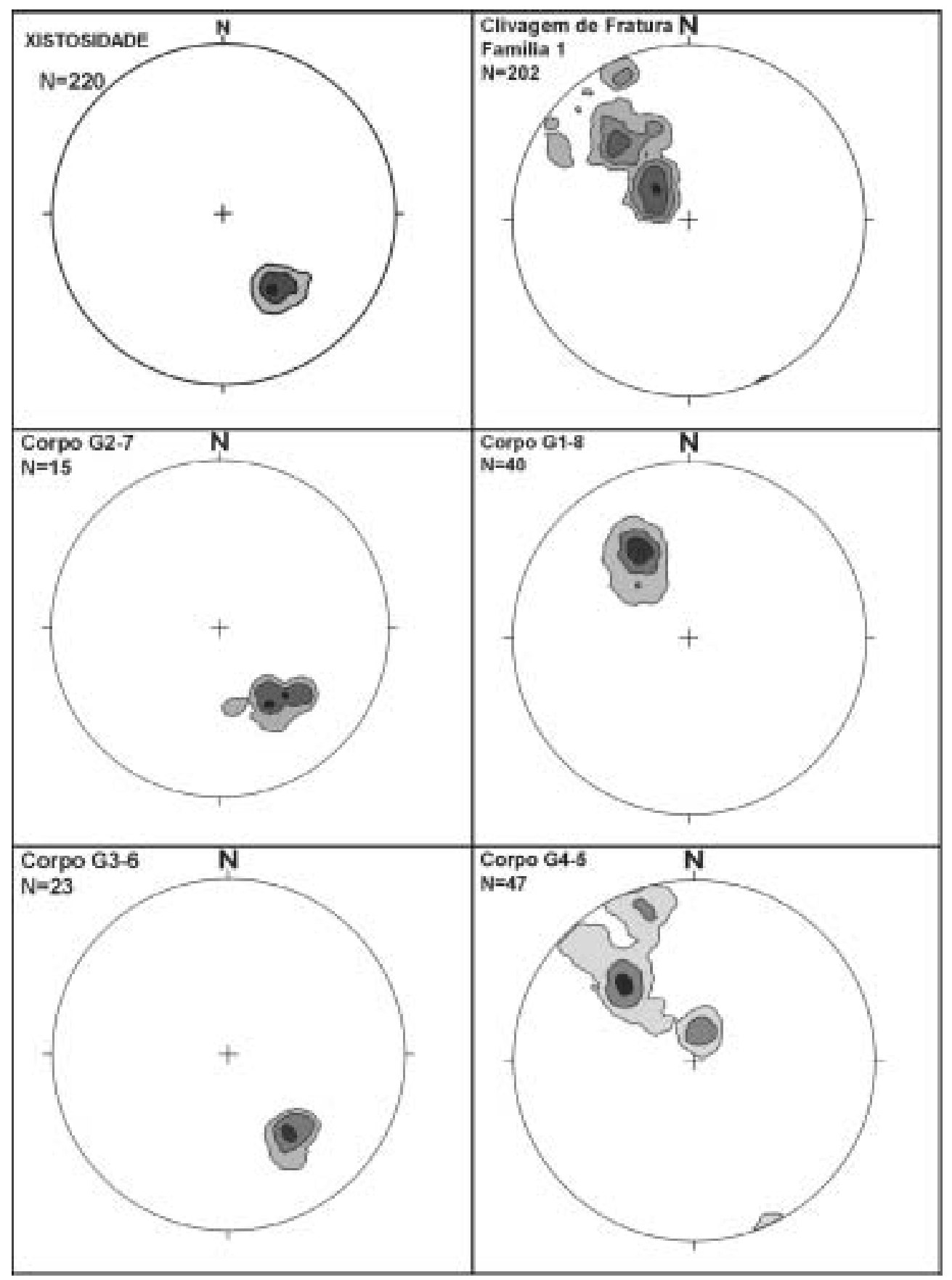

Figura 3. Diagramas de contorno dos pólos das estruturas encaixantes e dos contatos dos corpos pegmatíticos da Mina da Cachoeira. 


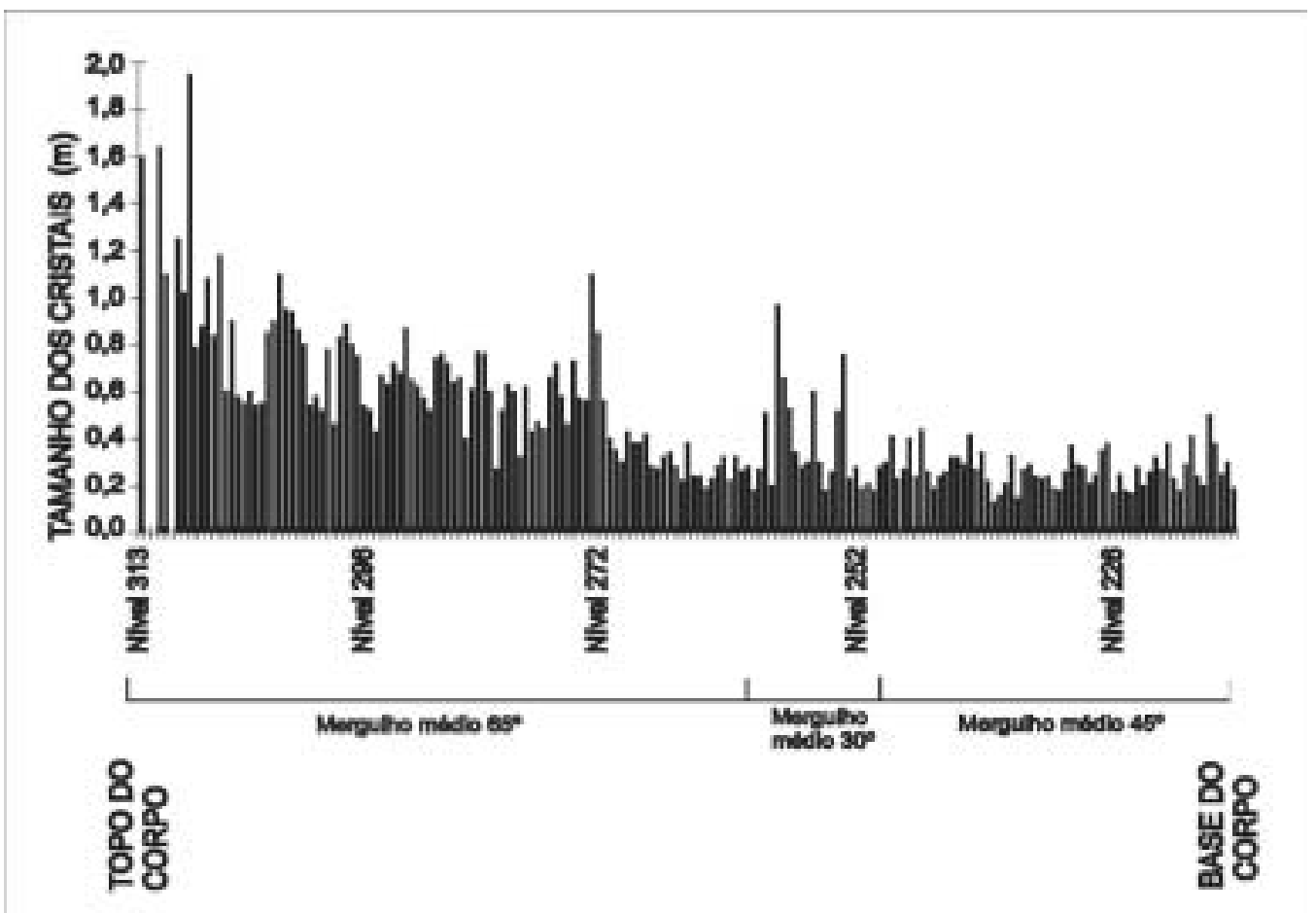

Figura 4. Histograma mostrando a variação do tamanho dos cristais de espodumênio do corpo G4-5 em relação aos níveis subterrâneos e mergulho médio do corpo.

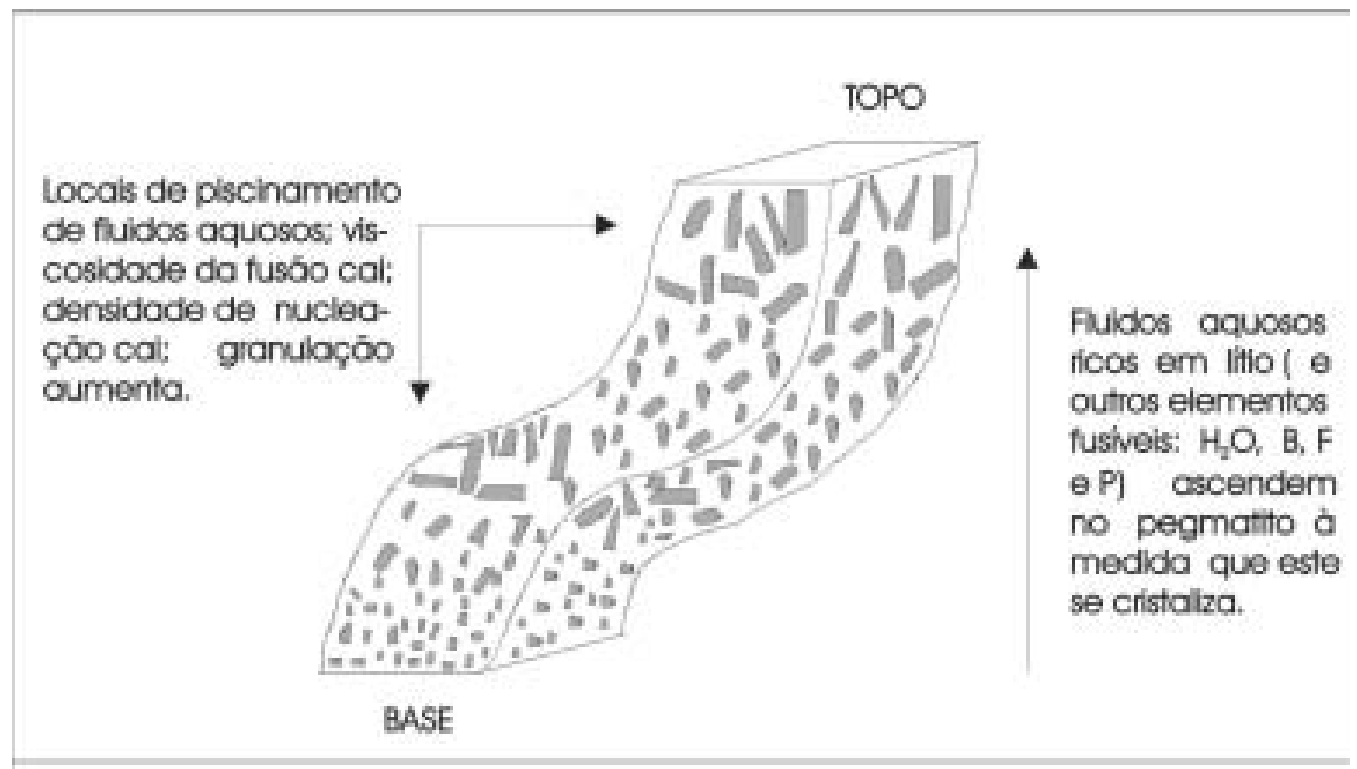

Figura 5. Esquema mostrando a tendência de crescimento dos cristais de espodumênio rumo ao topo do corpo e o fenômeno de "piscinamento" de fluido aquoso na porção de menor mergulho. Desenho fora de escala modificado de Pedrosa-Soares et al. (1997).

\section{MONITORAMENTOGEOQUIIMICO}

A composição química do espodumênio do corpo G4-5 é muito regular e não mostra desvio significativo da fórmula ideal ( $\left.\mathrm{LiAlSi}_{2} \mathrm{O}_{6}\right)$. Desta forma, para o monitoramento geoquímico do corpo G4-5 foi escolhido o feldspato potássico por ser o mineral que, além do espodumênio, está presente e bem distribuído em todo o corpo. As amostras foram coletadas com o objetivo de se obter informação geoquímica segundo o mergulho do corpo, desde o topo até a base.

Quanto maior a quantidade de substâncias fusíveis (e.g., Li, $\mathrm{P}, \mathrm{F}$ e $\mathrm{H}_{2} \mathrm{O}$ ), menores são a viscosidade e densidade de nucleação do magma pegmatítico, 
possibilitando maior crescimento dos cristais (London 1992). As afinidades geoquímicas das substâncias fusíveis com elementos traços, tais como $\mathrm{Rb}$ e $\mathrm{Ba}$, permitem realizar o monitoramento geoquímico do corpo pegmatítico por meio da análise do feldspato potássico. Por sua vez, os conteúdos de $\mathrm{Rb}$ e Ba no feldspato potássico tendem a aumentar, em relação ao crescimento dos cristais, no decorrer da cristalização primária dos grandes pegmatitos (Correia-Neves 1981, Cerný 1991).

Os dados obtidos demonstram que as razões $\mathrm{K} / \mathrm{Rb}$ e K/Ba diminuem sistematicamente da base para o topo do pegmatito, no mesmo sentido do aumento da granulação (Figura 6). Isto é também uma evidência do aumento de substâncias fusíveis, da base para o topo do pegmatito.

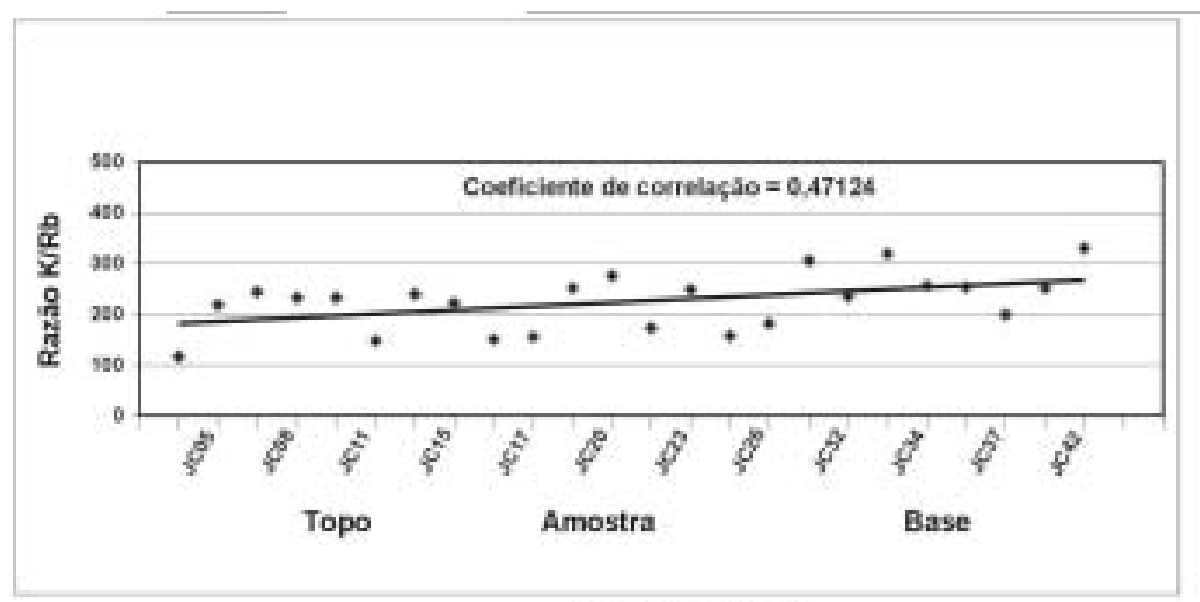

Gráfico 1

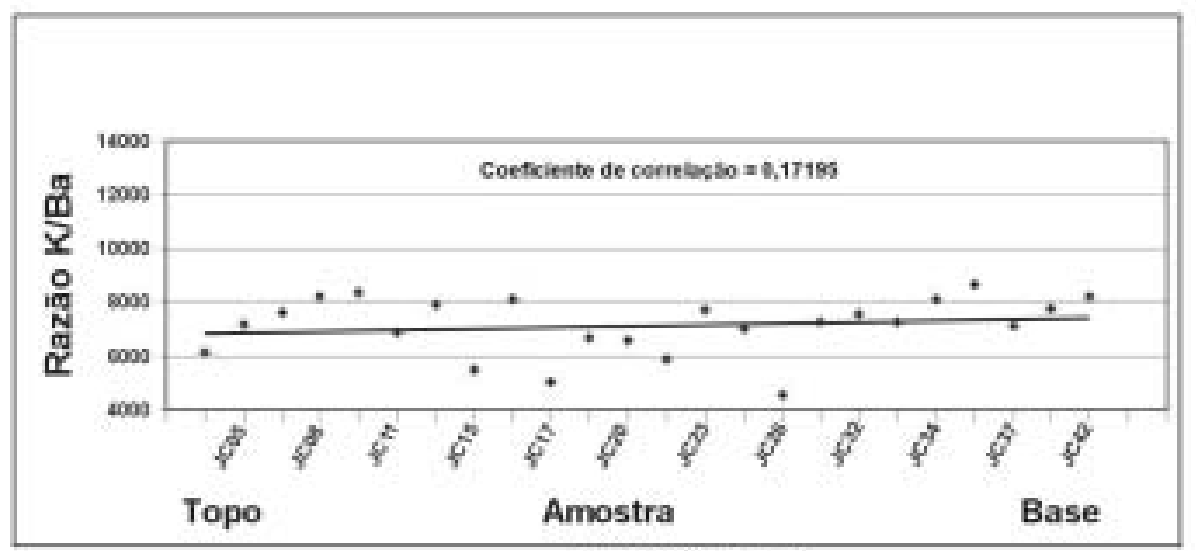

Gráfico 2

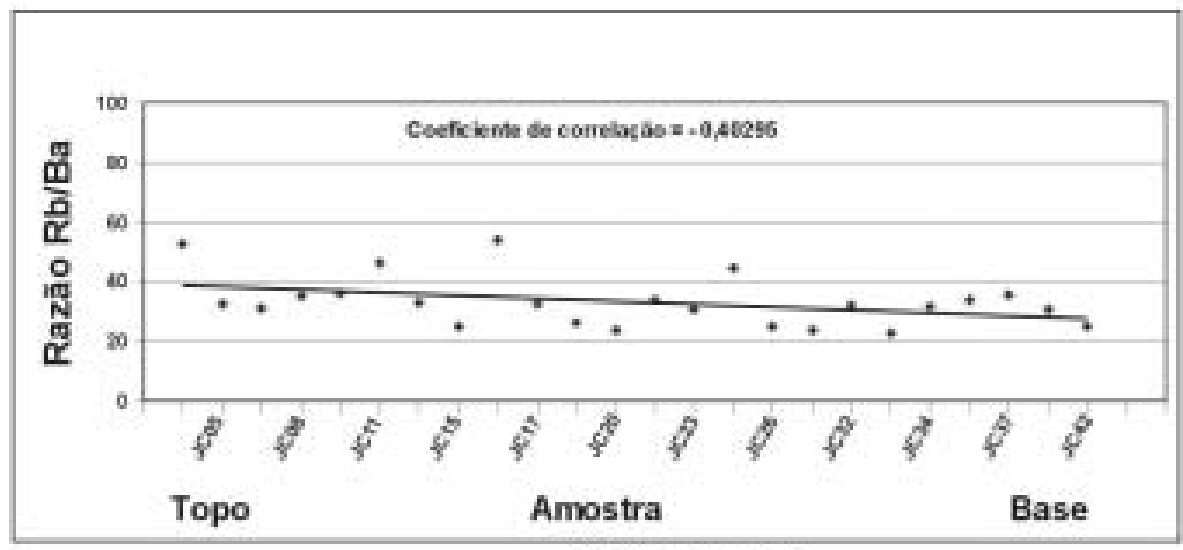

Gráfico 3

Figura 6. Diagramas mostrando a variação das razões $K / R b$ (1), $K / B a(2)$ e $R b / B a(3)$ em relação ao posicionamento da amostragem no corpo G4-5 (topo e base). 


\section{CONCLUSÕES}

O estudo do controle estrutural e das variações de granulação dos cristais de espodumênio dos pegmatitos demonstra que estes parâmetros podem ser usados como indicadores exploratórios.

O conhecimento do controle estrutural constitui a ferramenta essencial que permite prever mudanças de direção, mergulho, forma e de granulação dos pegmatitos homogêneos de grandes dimensões, como são os da Mina da Cachoeira. Estes parâmetros influenciam diretamente no planejamento e desenvolvimento de uma lavra subterrânea.

$\mathrm{O}$ monitoramento geoquímico, tal como aqui efetuado, pode ter utilidade prospectiva, se considerarmos que a granulação dos minerais pegmatíticos é, geralmente, um fator responsável pela recuperação econômica do pegmatito.

\section{AGRADECIMENTOS}

Os autores agradecem ao corpo técnico e administrativo da Companhia Brasileira de Lítio (CBL); ao $\mathrm{CNPq}$ e à FINEP pelos recursos financeiros para trabalhos de campo e laboratório; e a dois revisores anônimos da Revista GEONOMOS.

\section{REFERÊNCIAS BIBLIOGRÁFICAS}

CERNÝ, P. 1991. Rare-element granitic pegmatites. Part I: Anatomy and internal evolution of pegmatites deposits. Geoscience Canada, 18: 49-67.
CORREIA-NEVES, J.M. 1981. Pegmatitos Graníticos. Tese, Concurso Professor Titular. IGC, UFMG, 368 p.

LIMA, S.A.A., MARTINS-NETO, M.A., PEDROSA-SOARES, A.C., CORDANI, U.G., NUTMAN, A. 2002. A Formação Salinas na área-tipo, NE de Minas Gerais: Uma proposta de revisão da estratigrafia da Faixa Araçuaí com base em evidências sedimentares, metamórficas e idades U-Pb SHRIMP. Revista Brasileira de Geociências, 32:491-500.

LONDON, D. 1992. The application of experimental petrology to the genesis and crystallization of granitic pegmatites. Canadian Mineralogist, 30 (3): 499-539.

PEDROSA-SOARES, A.C., NOCE, C.M., SILVA, L.C., CORDANI, U.G., ALKMIM, F.F., BABINSKI, M. 2005. Orógeno Araçuaí: Estágio atual do conhecimento geotectônico. In: Simpósio Cráton do São Francisco, 3, Salvador. Anais, SBG, p. 243-246.

PEDROSA-SOARES, A.C., PINTO, C.P., CUSTÓDIO-NETTO, J., ARAÚJO, M.C., CASTAÑEDA, C., ACHTSCHIN, A.B., BASÍLIO, M.S. 2001a. A Província Gemológica Oriental do Brasil. In: C. CASTAÑEDA, J.E. ADDAD, A. LICCARDO (orgs.), Gemas de Minas Gerais. SBG, Belo Horizonte, p. 16-33.

PEDROSA-SOARES, A.C., NOCE, C.M., WIEDEMANN, C., PINTO, C.P. 2001b. The Araçuaí-West-Congo Orogen in Brazil: An overview of a confined orogen formed during Gondwanaland assembly. Precambrian Research 110:307323.

PEDROSA-SOARES, A.C., ROMEIRO, J.C.P., CASTAÑEDA, C. 1997. Papel do controle estrutural de pegmatitos graníticos em suas mineralizações: uma abordagem preliminar. In: SNET, 6, Pirenópolis, 1997, 327-329.

ROMEIRO, J.C.P., PEDROSA-SOARES, A.C., QUÉMÉNEUR, J.J.G., MARQUES, G.C.L. 1997. Controle estrutural dos pegmatitos litiníferos da Mina da Cachoeira, Companhia Brasileira de Lítio, Araçuaí, MG. In: SNET, 6, Pirenópolis, 1997, 341-343. 